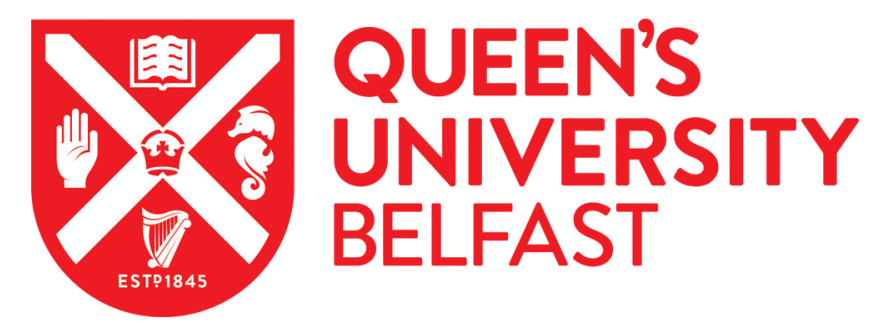

\title{
How can we make the psychiatric workforce more family focused?
}

Maybery, D., Foster, K., Goodyear, M., Grant, A., Tungpunkom, P., Skogoy, B. E., \& Lees, R. (2015). How can we make the psychiatric workforce more family focused? In A. Reupert, D. Maybery, J. Nicholson, M. Gopfert, \& M. V. Seeman (Eds.), Parental Psychiatric Disorder: Distressed Parents and their Families (3 ed., pp. 301-311). Cambridge University Press.

Published in:

Parental Psychiatric Disorder: Distressed Parents and their Families

Document Version:

Peer reviewed version

Queen's University Belfast - Research Portal:

Link to publication record in Queen's University Belfast Research Portal

Publisher rights

(C) Cambridge University Press 2015

This material has been published in Parental Psychiatric Disorder: Distress Parents and their Families by / edited by Reupert et al, and has been reproduced by permission of Cambridge University Press.

\section{General rights}

Copyright for the publications made accessible via the Queen's University Belfast Research Portal is retained by the author(s) and / or other copyright owners and it is a condition of accessing these publications that users recognise and abide by the legal requirements associated with these rights.

Take down policy

The Research Portal is Queen's institutional repository that provides access to Queen's research output. Every effort has been made to ensure that content in the Research Portal does not infringe any person's rights, or applicable UK laws. If you discover content in the Research Portal that you believe breaches copyright or violates any law, please contact openaccess@qub.ac.uk. 


\section{How can we make the psychiatric workforce more family focused?}

Dr Maybery, Dr Foster, Dr Goodyear, Dr Grant, Dr Tungpunkom, Bjorg Eva Skogoy MSW and Dr Lees

Multiple international studies indicate that very few families or children receive interventions or support when their relative with mental illness is receiving treatment (e.g. Rummel-Kluge, Pitschel-Walz, Bäuml \& Kissling 2006). This chapter focuses upon workforce issues, particularly how we can support the psychiatric workforce to be family focused. Initially, the chapter outlines what we mean by family approaches and then overviews our conception of a continuum of family-focused care and expectations for psychiatric agencies and workers. A brief theoretical overview of family focused care is then outlined followed by information about barriers and enablers to family focused practice. The chapter ends with reflections from multiple countries regarding the current state of family focused practice and potential ways forward in each country.

As outlined throughout this book, mental illness can be disabling, but when that person is a parent, his or her children can also be adversely affected. Being a child of such parents significantly increases the likelihood for children acquiring a mental disorder themselves compared to other children in the community (Hosman, van Doesum \& van Santvoort, 2009) along with a multitude of associated risks (e.g. emotion, school, relationship problems). At the same time, research has clearly demonstrated the benefits of family focused practice to the service user parent, as well as his or her children and other family members (Siegenthaler, Munder \& Egger, 2012). However the world over, the psychiatric workforce rarely seems to respond to children and families where a parent has a mental illness. Children living in such families have been described as 'hidden' because workers are often unaware that service users are parents with dependent children (Fudge \& Mason, 2004). A study of German, Austrian and Swiss psychiatric institutions found that only two percent of family members received any form of psycho-education (Rummel-Kluge et al., 2006). That means 98 percent of family members received no information about mental illness from these psychiatric institutions. 


\section{Supporting families in mental health services}

History offers an explanation for why psychiatric services have not engaged with families.

Originally the family was conceptualised as detrimental to the recovery of the individual until family intervention research illustrated the role of the family as a factor that improves treatment outcomes of the person with mental illness (Miklowitz et al., 2003). At the same time workers traditionally played an expert role, at the expense of involving and working collaboratively, with families and parents. The family advocacy movement in the 1990's highlighted the impact and additional support needs of family members caring for people with mental illness. In addition, the perspective on children has also shifted, from being passive to active with the United Nations Convention on Rights of the Child (1989), stating that children have a right to both protection and participation. The convention encourages parents to consider the rights of the child in a manner consistent with their evolving development and that legislators should create a policy environment that both protects children's rights and encourages an environment where the children can grow and reach their potential. We contend that both the parent and the child have the right to have their needs acknowledged and met, and the family as a whole needs to be respected and supported when parents have mental health problems.

Traction for family-centred practice occurred in the 1980's and 1990's in the disability and education sectors and focused upon child medical or emotional problems and most commonly children with a disability (Law et al., 2003). Family centred practice began from a group of parents and workers who believed that parents were experts in their children's lives and had a key role to play in their treatment. It is only recently that there have been calls for family centred practice in other fields, such as adult mental health or the drug and alcohol sector typically where the intervention is adult focused (Maybery \& Reupert, 2009).

\section{Theoretical underpinnings of Family-focused care}

Thus our theoretical perspective on family focused workforce practices in psychiatric settings, particularly adult services, has been informed by the literature on family-centred practice. The term 'family-centred practice' refers to a philosophy and method of service delivery that emphasizes a partnership between families and service providers (Dempsey \& Keen, 2008). At their heart, family centred services provide families with opportunities to be actively involved in decisions and choices, as well as actions to achieve desired goals and outcomes (Dunst et al., 2007). Workers who employ family centred practice recognise the 
central place of the child/parent relationship in achieving positive outcomes for children, and acknowledge that parents are the experts about their children's needs. In contrast to professional-centric practice, or practice that views the worker as the expert, family centred practice supports the role of the family in the healthy development of children.

While the principles of a family centred service were further developed in the 1990's they have been expanded since by Dunst and colleagues (e.g. Dunst, Trivette \& Hamby, 2007). Table 1 illustrates how the four principles can be applied to families where a parent has a mental illness.

Table 1: Principles of family focused practice as applied to practice and actions.

\begin{tabular}{|l|l|}
\hline \multicolumn{1}{|c|}{ Principle } & \multicolumn{1}{c|}{ Meaning for practice and action } \\
\hline $\begin{array}{l}\text { The family is central to } \\
\text { the lives of individuals. }\end{array}$ & $\begin{array}{l}\text { This means identifying the family as a unit of attention and } \\
\text { action rather than the parent as having or being the 'problem' }\end{array}$ \\
\hline $\begin{array}{l}\text { Maximizing the parent } \\
\text { and families' choice and } \\
\text { ability to make decision } \\
\text { making. }\end{array}$ & $\begin{array}{l}\text { Rather than being profession centric in decision making, } \\
\text { acknowledge that parents know their children best, know what } \\
\text { is best for their children and have ultimate care for their } \\
\text { children. }\end{array}$ \\
\hline Being strengths-based & $\begin{array}{l}\text { Apply a strengths-based as opposed to a deficit or disease } \\
\text { perspective of the parent and family. Rather than 'blame' the } \\
\text { parent for the mental health issue, workers recognise that all } \\
\text { families have strengths that can be further developed and used } \\
\text { in problem solving. }\end{array}$ \\
\hline All families are different & $\begin{array}{l}\text { Recognise that all parents and families are different that } \\
\text { require competent services that value diversity and multiple } \\
\text { perspectives. }\end{array}$ \\
\hline
\end{tabular}

Dunst and colleagues (2007) distinguish between relational and participatory help giving practice. The former involves workers empathizing and taking a non-judgemental stance towards families and participatory involves encouraging family resources to meet their individual needs. In the psychiatric workforce, Grant (2014) identified four, core familyfocused activities including: (1) identifying individual family member needs (2) supporting parenting capacity (3) engaging and supporting children and other family members and (4) collaborating with others.

But what are the actual practices that we expect from the psychiatric workforce? 


\section{Continuum of family focused activity in the psychiatric setting: policies and practices}

While we have considered 'family-centred practice' as a theoretical underpinning of family focused activity the terms 'family sensitive, inclusive, centred and focused' are commonly employed in the field, emphasising different positions regarding the nature of family involvement in care and terms to encourage practice. In general however, the terms all seek to involve families in routine care. Notably absent however is family therapy. While this form of therapy can be very effective for families, it is a specific therapeutic approach rather than an approach to mental health care more broadly.

Regarding parental mental illness, our perspective is that family focused care respects the role of the family, and recognises the impact of parents' mental illness on their parenting, children and other family members. Before discussing what this might mean in terms of workers' specific practices we need to consider the broader context within which mental health care is provided. In this section we include discussion of specific policy and procedures at the agency level and leave the larger national, province or state policy perspective to be discussed elsewhere (see Chapter xxx).

In mental health, family-focused practice can exist on a continuum ranging from essential recognition of parent status, through to a variety of specific practices (Foster, O'Brien \& Korhonen, 2012). Figure 1 outlines a continuum of increasing intensity of practices that involve families in routine care. The dual continuum first requires that psychiatric agencies move their policies and procedures to consider the parent, family and children. The most basic policy response is when the parent is being admitted to the psychiatric institution. All psychiatric agencies need to have a policy that ensures that parenting status is identified, recorded and that children are safely situated. Moving along the continuum, a more comprehensive agency policy would support ongoing and comprehensive parent engagement, with agencies are obliged to include parenting, families and children, as part of the parent's treatment (see recovery and parenting chapter). It is also recommended that agencies provide family friendly visiting areas or rooms and policies that encourage workers to be family focused in their practices. At the extreme end, agencies might also consider, where appropriate, physically accommodating all family members within the psychiatric service. This is now becoming common with mother-baby units for very young children but could also be expanded to include older children and family members. 
The second dimension of Figure 1 outlines the work that might be undertaken in a family focused psychiatric setting. We propose that all workers must acquire a 'basic family skill set' with the most basic practice being that the worker engages with the parent regarding their parenting and their children. For example, on intake to the service we believe that a worker must enquire 'Do you have children'? and 'Are they currently safely in the care of someone'? Considering the importance of involving families in routine care, this is a bare minimum practice requirement for all workers. We also believe the basic skill set must include being able to assess a parent's parenting skill and the family circumstances in which the children are living (Berman \& Heru, 2005). It has been recommended that this minimum skill set includes a process for identifying a service user's children, the ability to initiate relationships with the service user's family members, an assessment of the parent/s, child/ren and family's basic needs, the provision of mental health literacy to each family member, collaborative practice with other key agencies, and clear and sensitive procedures for referrals within confidentiality agreements (Maybery \& Reupert, 2009; Foster et al., 2012). 
Figure 1: Continuum of family focused psychiatric agency and workforce activities.

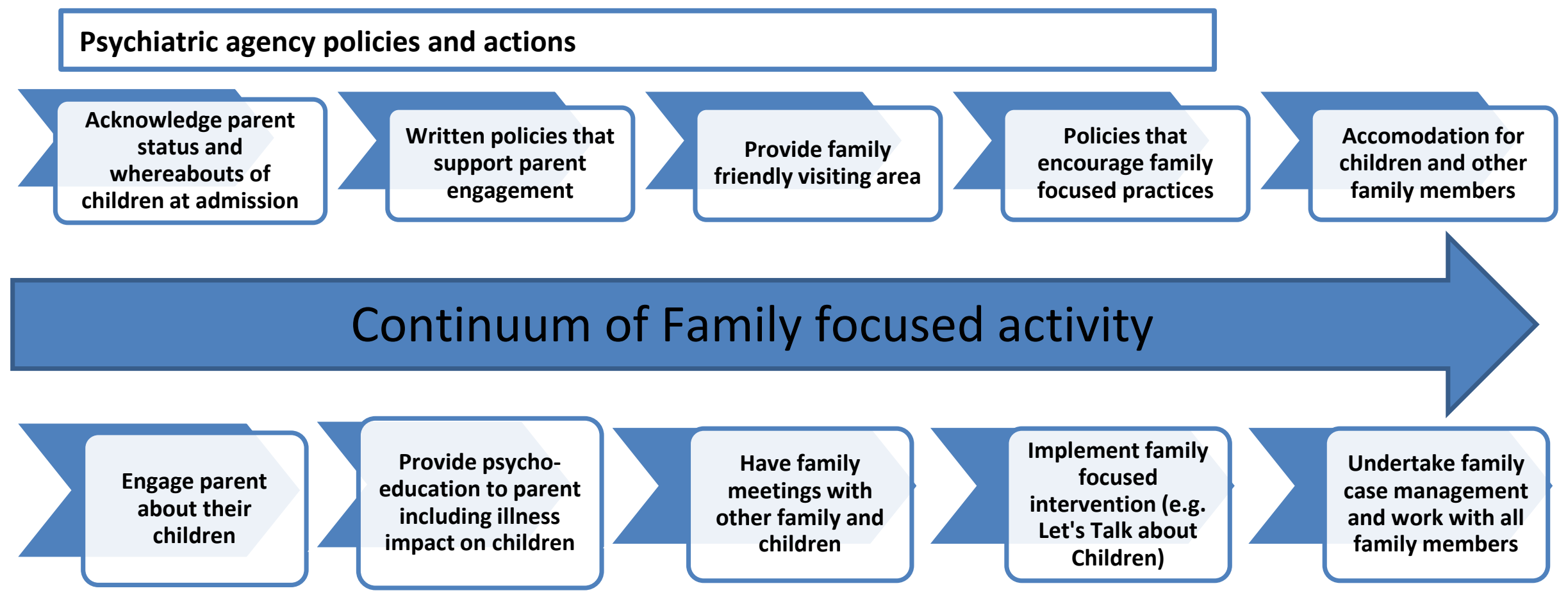

Psychiatric workers family focused practices 
Further along the continuum is the provision of psycho-education to parents, children and families. Psycho-education typically focuses on education about mental illness and treatment and has been shown to be particularly effective in the treatment of schizophrenia and by reducing relapse and re-admission rates and in reducing burden on family members (McFarlane et al., 2003). Another important worker skill is in delivering family focused strategies that address early intervention and the prevention of mental illness in children. A recent meta-analysis of the impact of family interventions on children concluded that "The risk of developing the same mental illness as the parent was decreased by $40 \%$..."

(Siegenthaler et al., 2012). These prevention interventions are generally empowering for the parent and enjoyable for the mental health worker and are commonly brief (e.g. 2-5 sessions) and implemented in combination with the current practice of the worker. The interventions aim to give adult practitioners the tools to engage with parents and children and to develop the parent's strategies for talking to their children about mental illness, promoting child and family strengths and typically empowering the parent in his or her parenting role.

\section{Constraints on family-focused practice}

The efficacies of family focused approaches have empirical support. In a meta-analysis Dunst et al. (2007) found that the more family-focused workers were, the more service users were satisfied with workers and their programs, and had stronger self-efficacy beliefs. However, while the relevance and importance of family-focused practice has been highlighted in the previous section, the literature indicates multiple barriers to workers undertaking this work. In a systematic review of the literature, Maybery and Reupert (2009) summarised the literature (see Figure 1 below) according to; the organisation, the workforce and the parent and family members. 


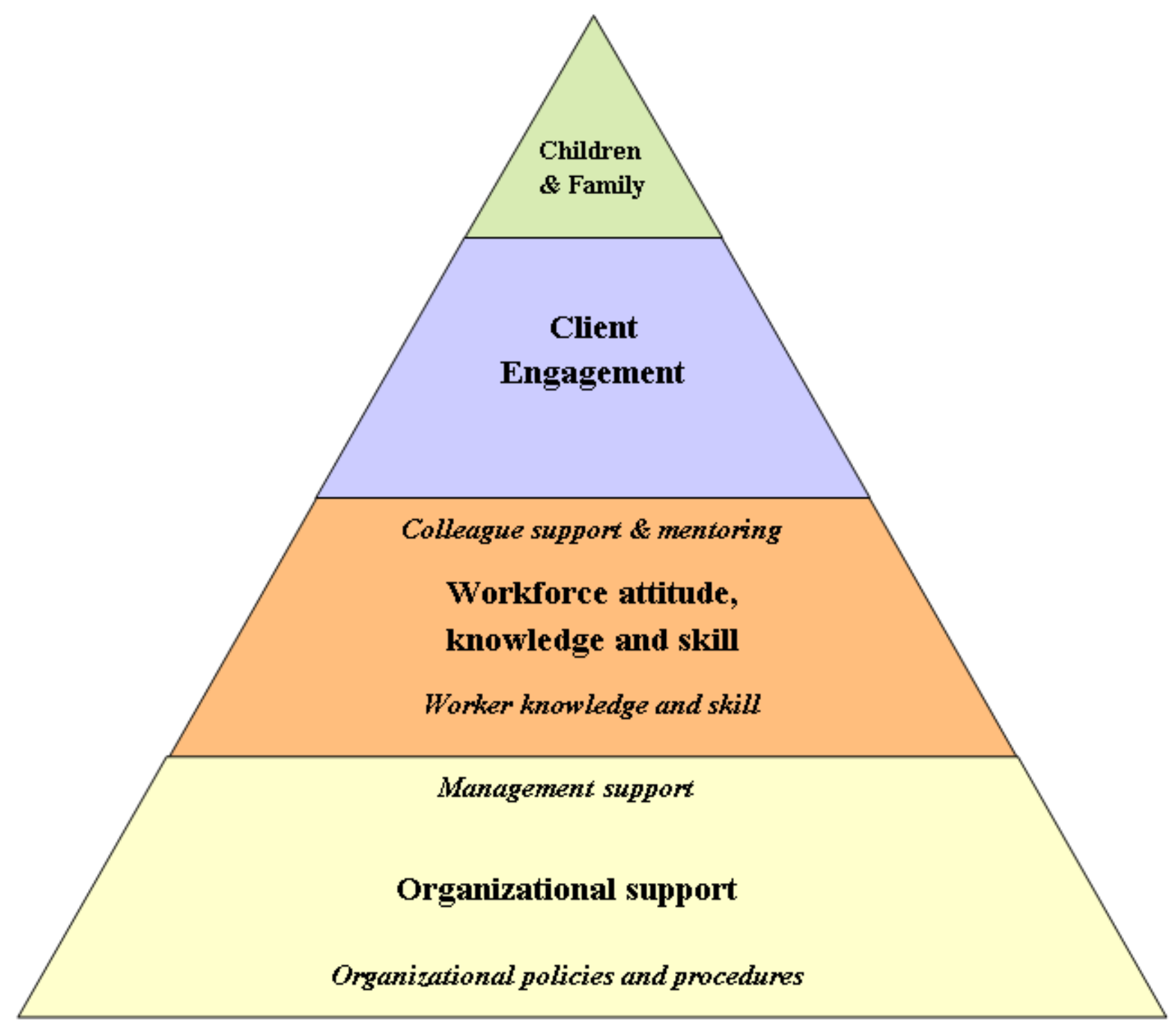

Figure 2: Points of influence affecting family focused workforce change (taken from Maybery \& Reupert, 2009).

While discussed in detail elsewhere (see Maybery \& Reupert, 2009) the key points can be summarised as follows:

Organisational support: The bedrock for workforce change is policies and management support that acknowledge the families and children of service users and encourages family focused work.

Workforce attitude, knowledge and skill: Ensure that the mental health workforce is skilled and knowledgeable about the impact of parental mental illness on families and children able to respond with family focused practices. 
Client, children and family engagement: The ultimate hurdle to family focused practice is the availability and willingness of the parent and children to engage with the worker.

There have been other factors considered important including interagency collaboration (Maybery \& Reupert, 2009) and personal factors highlighted by more accomplished nurses at family focused practice drawing upon their personal attributes, including their own parenting, life and work experience (Grant, 2014). In addition, nurses working in a community setting undertook many more family focused practices than did those working in the acute inpatient psychiatric setting (Grant, 2014). Profession differences have also been noted with social workers being found to engage in more family focused practice compared to psychiatric nurses and psychologists (Maybery et al., in press). Further, the greatest learning need to these professions in regard to family focused practices have been identified for psychologists as needing to know most about parenting, doctors most about how they could support families and nurses and social workers more about parenting and child development. Interestingly, knowledge about parenting was rated as the greatest learning need for all professions (Whitman et al., 2009).

\section{International workforce responses to family-focused practice}

To illustrate the evidence and practice on family-focused care in various contexts, the following section briefly outlines the psychiatric workforce situation in several different countries. The 'state of play' is outlined for each country including where the majority of effort has been centred. Finally, recommendations for the direction that each country could take to increase family focused practice in the next 5-10 years is outlined.

\section{Australia}

Australian efforts to enhance workforce capacity have focused upon resource development, policy changes and workforce research. The Australian National COPMI initiative has developed multiple resources for parents, children and families and workforce training materials. Generally these have been online e-learning resources and focused on awareness raising, training in specific interventions or providing information for parents, children and families (see http://www.copmi.net.au/ and the e-learning chapter for more detail). The COPMI initiative has also harnessed the work of many parental mental illness focused groups and "champions" across Australia that have systematically advocated for a focus on families within their individual workplaces. COPMI have also led the way in terms of policy with the 
'Principles and Actions for Services and People Working with Children of Parents with a Mental Illness' document (AICAFMHA, 2004). Increasingly, government policy is also beginning to acknowledge parenting and child related needs. Multiple research studies have also been undertaken over the last 10 years in Australia including practice audits, workforce surveys and evaluation studies.

At the same time, more needs to be done in Australia to systemically identify the parenting status of clients, and to ensure that appropriate referral and/or intervention programs are in place that addresses the needs of families. A goal for Australia might be to ensure that all psychiatric workers are routinely taking the first step in the continuum in Figure 1 (i.e. asking 'are you a parent, are your children safe, do they require some support?') and that all parents, children and families receive basic psycho-education and family-centred interventions such as Family Focus or Let's Talk about Children.

\section{Canada}

One of the most "grassroots" efforts to improve workforce responses to families in Canada has been the development of community based forums. Sponsored by a community of practice in British Columbia known as the Provincial Working Group on Supporting Families with Parental Mental Illness, forums have brought together practitioners from professional and paraprofessional ranks in adult mental health, child and youth mental health, child welfare and schools along with family members with lived experience. Guided by a manual a community self-assessment encourages forum attendees to move from education to action based on the situation in their community. Evaluation has shown shifts in worker practice including a greater belief in the ability of families despite dealing with mental illness and greater passion for their work. Similar collaborative efforts at a systems level are typified by work in Manitoba by Professor Elaine Mordoch who brought together policy makers from the various agencies and universities to develop a strategy for inquiry and service to families with parental metal illness.

Interest in Ulysses Agreements (advance care plans) has brought together mental health workers and child welfare workers for case specific action and learning. Anecdotal information from a Ulysses Agreement project in the Fraser Health Region, BC, has demonstrated the strong desire of child welfare workers to respond supportively to parents with mental illness. However these same child welfare workers have a perceived need for 
outside specialized staff, knowledgeable regarding mental illness, child development and skilled in wrap-around -collaborative care models. A project in Toronto initiated in 2014 has brought dedicated adult mental health staff into a child welfare agency for a team approach to address the need of the child welfare system to appropriately deal with parental mental health factors.

Since 2010 policy development in British Columbia has been prompted by the publication of a 10 year mental health plan, Healthy Minds, Healthy People that outlines key practice strategies related to parental mental illness. As well, policy and practice have been shaped by the tragedy of three children murder by their father who suffered by undiagnosed mental illness and substance misuse. The document Safe Relationships, Safe Children and subsequent action plans has led to pilot projects directed from government, requiring agencies delivering adult mental health, child welfare and women's domestic services to have to plan for ways to work collaborative, identify mental illness and substance misuse in parents and together consider the needs of the children. Through these high level initiatives what was largely a voluntary workforce strategy, is now on the cusp of becoming required practice. Finally, the Institute for Families, a national organization led by parents of children with mental illness has sponsored a first consensus conference (2014) on the term, Family Smart. Unique to this project is its' consumer leadership and efforts to advance a set of principles regarding practice and organization that can be identified as "Family Smart". These efforts promise a metric by which mental health organizations and practice can be assessed in relation to their degree of appropriate family centered care.

\section{Ireland}

During the last decade there has been investment of resources in the Irish childcare system and a number of National policy initiatives and strategies to facilitate services to become child friendly including a greater emphasis on prevention, early intervention and interagency collaboration. For example Children First (Department of Children and Youth Affairs [DCYA], 2011) explicitly outlines the roles, responsibilities and procedures of mental health and addiction services in safeguarding the interests and well-being of service users' children. In adult services A Vision for Change (Department of Health and Children, 2006) also acknowledges the needs of parents who have mental illness, their children and families and the important role that mental health professionals should play in supporting them. These recommendations place an onus on mental health professionals, in Irish mental health 
services, to work closely across service boundaries, to develop protocols, policies and programmes in consultation with service users, their children and families. However, the recommendations within A Vision For Change (Department of Health and Children, 2006) appear to have resulted in limited impact. While there is not yet a focused national policy implementation framework or legal obligation for mental health professionals to translate recommendations into practice, there remains a need for national investment including, including training and guidelines to enable mental health professionals to meet these recommendations

\section{Norway}

Norwegian efforts to enhance workforce capacity have focused on awareness raising, education programs, followed by changes in policy and law. From 1998 to 2004 the Directorate for Health and Social Affairs funded a national education program; "When mum or dad has a mental illness" led by the non-government organization, Adults for Children (see www.vfb.no). In later years a Nordic Forum brought together and inspired a network for the "champions" in the area of family mental illness. This led to new practices inspired by the work of Professor William Beardslee, the development of BAPP-groups for children (Rimehaug, 2014) and www.Morild.org, a webpage and discussion group for adolescents (Trondsen, 2012). An evaluation found that most initiatives were small and that a family focus in the mental hospitals was still scarce (Aamodt \& Aamodt, 2005) and reported a need to strengthen children's legal rights to information and help. From 2007-2014, the Ministry of Children, Equality and Social Inclusion funded "The Model Municipality project"to develop better services for families with mental illness and substance abuse problems and their children 0-6 years. From 2007, the Ministry of Health and Care Services funded several development projects in the specialist-services. A Danish model "Familieambulatoriet" (Olofson, 2005) following families with severe problems from 0-6 yrs, are spread to new hospitals. "BarnsBeste” a national competency network is established. They develop and systematize information about changes in family focused practise (www.barnsbeste.no). Elearning resources, national networks for coordinators, user-consultants and researchers have been developed.

In 2010, Norway was a world leader by being the first country to give "Children as next of kin" lawful rights to information and follow up when any of their parents have mental illness, substance abuse problems or severe somatic illness. This law means that all health personnel 
are obliged to help parents to have conversations in the family about how their children are affected by their illness, and secure necessary follow up. The specialist-service has to establish "Child Liaison (Responsible) Personnel" to systematize and support a child and family focus. Research projects are currently underway that will study the implementation of these changes and the outcomes for parents and children.

\section{Thailand}

Thailand's efforts to enhance workforce capacity in mental health have focused upon resource development, policy changes and workforce research. Mental health care has been integrated into general health care systems establishing mental health clinics within the general hospital setting. However, these mental health agencies are not specifically parent focused. The mental health department under the public health ministry of Thailand has led the way particularly in resource development. This has included developing multiple resources for parents, children and families and workforce training materials and has led to greater urgency to act and to focus on enhancing the resiliency of the family to decrease mental health problems and promote mental health in family members. Recently, child and adolescent and family practice have also raised awareness of family focused practice. However, more child and adolescent psychiatrists are likely to be trained in future with a new curriculum being developed and greater family and child research needs to be undertaken.

At the same time, more needs to be done to systematically identify the parenting status of clients, and to ensure that appropriate referral and/or intervention programs are in place that addresses the needs of families. An implementation strategy that assumes an early intervention, public population approach is also required. The last ten years have seen considerable developments in resources and knowledge specifically in adult mental health and their family. The next decade must broadly focus upon children and adolescents and their family.

\section{Conclusion}

Throughout this chapter, we have discussed how the psychiatric workforce can be supported to be family focused in their practice with parents with mental illness and their children and families. Evidence from international studies demonstrates that implementation of family focused interventions has a strong positive influence on the wellbeing and outcomes of 
children and families. As an international group we have also outlined the policy and service provision issues that impact provision of family focused practice in a range of countries.

However there are other countries not represented in this discussion.

To reduce the inter-generational transmission of mental illness globally and strengthen child and family wellbeing across countries, there is a clear and important need for the mental health workforce to respond effectively to the needs of children and families. The evidence to date indicates that most mental health professionals are deficient in knowledge and skills about children and families and in effective interagency collaboration - particularly with other family workers. As identified in the chapter, there are a number of points of influence that can be addressed in order to implement family focused practice across disciplines, and to translate evidence on family focused practice into workforce change. Strategies need to be multi-faceted and target organisational, workforce, and child and family factors in order to effect this change. At the workforce level, identification of service users' parental status on intake, and ascertaining their child/ren's safety and care, is a first step in the continuum of family focused practice towards ensuring better outcomes for children and family. Provision of information on mental illness to children and families, and supporting parenting for service users, are further steps towards effective care for families. Mental health professionals are in prime positions to enact these strategies and to advocate for systemic policy implementation in family focused mental health service provision. 


\section{References}

Aamodt, L. G., \& Aamodt, I. (2005). Tiltak for barn med psykisk syke foreldre (Interventions for children with mentally ill parents). Report. RBUP Øst/Sør.

AICAFMHA (2004). Principles and actions for services and people working with children of parents with a mental illness. Adelaide, SA: Australian Infant Child Adolescent and Family Mental Health Association Ltd.

Berman, E., \& Heru, A. M. (2005). Family Systems Training in Psychiatric Residencies. Family Process, 44, 321-335.

Department of Children and Youth Affairs. (2011). Children first: National guidance for the protection and welfare of children. Dublin: Department of Children and Youth Affairs (DCYA) Retrieved from http://www.hse.ie/eng/services/publications/services/children/CF2011.pdf.

Department of Health and Children. (2006). A vision for change. Report of the expert group on mental health policy. Dublin: The Stationery Office. Retrieved from http://www.dohc.ie/publications/pdf/vision_for_change.pdf.

Dempsey, I., \& Keen, D. (2008). A Review of Processes and Outcomes in Family-Centered Services for Children With a Disability. Topics in Early Childhood Special Education, 28, 42-52.

Dunst, C. J., Trivette, C. M., \& Hamby, D. W. (2007). Meta-analysis of family-centered helpgiving practices research. Mental Retardation and Developmental Disabilities Research Reviews, 13, 370-378.

Foster, K., O'Brien, L., \& Korhonen, T. (2012). Developing resilient children and families when parents have mental illness: A family-focused approach. International Journal of Mental Health Nursing, 21, 3-11.

Fudge, E., \& Mason, P. (2004). Consulting with young people about service guidelines relating to parental mental illness. Advances in Mental Health, 3, 50-58.

Grant, A. (2014). Registered psychiatric nurses' practice with parents who have mental illness, their children and families, within general adult mental health services in Ireland. $\mathrm{PhD}$ Thesis, Monash University, Melbourne, Australia.

Hosman, C. M. H., van Doesum, K. T. M., \& van Santvoort, F. (2009). Prevention of emotional problems and psychiatric risks in children of parents with a mental illness in the Netherlands: I. The scientific basis to a comprehensive approach. Advances in Mental Health, 8, 250-263.

Korhonen, T., Vehviläinen-Julkunen, K., \& Pietilä, A. (2008). Implementing child-focused family nursing into routine adult psychiatric practice: Hindering factors evaluated by nurses. Journal of Clinical Nursing, 17, 499-508. 
McFarlane, W. R., Dixon,L., Lukens, E., \& Lucksted, A. (2003). Family psychoeducation and schizophrenia: A review of the literature. Journal of Marital and Family Therapy, 29(, 223-245.

Maybery, D., \& Reupert, A. (2006). Workforce capacity to respond to children whose parents have a mental illness. Australian and New Zealand Journal Psychiatry, 40, 657-664.

Maybery, D.J. \& Reupert, A.E. (2009). Parental mental illness: A review of barriers and issues for working with families and children. Journal of Psychiatric and Mental Health Nursing, 16(9), 784-791

Miklowitz, D. J., George, E. L., Richards, J. A., Simoneau, T. L., \& Suddath, R. L. (2003). A randomized study of family-focused psychoeducation and pharmacotherapy in the outpatient management of bipolar disorder. Archives of General Psychiatry, 60, 904-912.

Olofsson, M. (2005). Omsorg for gravide og småbørnsfamilier med rusmiddelproblemer: Familieambulatoriets interventionsmodel. Sundhedsstyrelsen.

Reupert, A., Foster, K., Maybery, D., Eddy, K., \& Fudge, E. (2011). "Keeping Families and Children in Mind": An evaluation of a web based workforce resource. Child \& Family Social Work, 16, 192-200.

Reupert, A.E. \& Maybery, D.J. (2007). Families affected by parental mental illness: Issues and intervention points for stakeholders. American Journal of Orthopsychiatry, 77, 362-369.

Rimehaug, T. (2014). The ecology of sustainable implementation: Reflection on a 10-year case history illustration. Zeitschrift für Psychologie, 222, 58-66.

Rummel-Kluge, C., Pitschel-Walz, G., Bäuml, J., \& Kissling, W. (2006). Psychoeducation in schizophrenia - results from a survey of all psychiatric institutions in Germany, Austria and Switzerland. Schizophrenia Bulletin, 32, 765-775.

Siegenthaler, E., Munder, T., \& Egger, M. (2012). Effect of preventive interventions in mentally ill parents on the mental health of the offspring: Systematic review and metaanalysis. Journal of the American Academy of Child \& Adolescent Psychiatry 51, 8-17.

Trondsen, M. V. (2012). Living With a Mentally Ill Parent: Exploring Adolescents' Experiences and Perspectives. Qualitative Health Research, 22, 174-188.

United Nations (1989). Convention on the Rights of the Child. Retrieved 28th May 2014 from http://digitalcommons.ilr.cornell.edu/child/8/

Whitman, J., Eddy, K., Maybery, D., Reupert, A., \& Fudge, E. (2009). Use of a web-based Delphi study in the development of a training resource for workers supporting families where parents experience mental illness. International Journal of Mental Health Promotion, 11, 4252. 